\title{
KEBIASAAN SARAPAN SEBAGAI DETERMINAN PRESTASI BELAJAR SISWA MTs NURUL FALAH JUAI KABUPATEN BALANGAN
}

\section{BREAKFAST HABITS AS A DETERMINAN LEARNING ACHIEVEMENT STUDENT OF THE MTS NURUL FALAH JUAI, BALANGAN REGENCY}

\author{
Erwin Ernadi ${ }^{*}$, M. Bahrul Ilmi² \\ 1,2 Fakultas Kesehatan Masyarakat, Universitas Islam Kalimantan (UNISKA) MAB \\ Banjarmasin \\ Jl. Adhyaksa. No.2. Kota Banjarmasin, Kalimantan Selatan. Indonesia \\ *Email : ererwin3@gmail.com
}

\begin{abstract}
ABSRACT
Breakfast is the first food menu consumed by someone. Without breakfast someone will experience hypoglycemia or glucose levels below normal. Hypoglycemia results in trembling, dizziness and pain concentrating. This study aims to find out the breakfast habits as a determinant of the learning achievement of students of the same junior high school in the District of Juai, Balangan Regency. This type of research is analytical with cross sectional study approach. The subjects of the study consisted of men and women in the MTs Nurul Falah school in the District of Juai, Balangan Regency. The

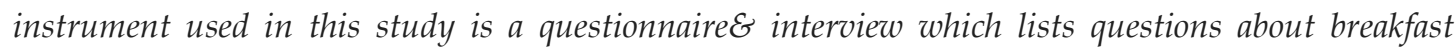
habits as a determinant of student learning achievement. The data is then processed and analyzed by chi square test to test the research hypothesis. Based on research results, there is a relationship between breakfast habits with learning achievement. It is expected that there will be an increase in information about healthy lifestyles both for educational institutions and for parents of students.
\end{abstract}

Keywords: Habits Breakfast; Junior High School; Learning Achievements; MTs Nurul Falah.

\begin{abstract}
ABSTRAK
Sarapan adalah menu makanan pertama yang di konsumsi seseorang. Tanpa sarapan seseorang akan mengalami hipoglikemia atau kadar glukosa dibawah normal. Hipoglikemia mengakibatkan tubuh gemetaran, pusing dan sakit berkonsentrasi. Penelitian ini bertujuan untuk mengetahui kebiasaan sarapan sebagai determinan prestasi belajar siswa SMPN Sederajat di Kecamatan Juai Kabupaten Balangan. Jenis penelitian ini yaitu analitik dengan pendekatan cross sectional study. Yang menjadi sampel penelitian yaitu semua siswa terdiri dari laki-laki dan perempuan yang terdapat pada sekolah MTs Nurul Falah di Kecamatan Juai Kabupaten Balangan. Instrumen yang digunakam dalam penelitian ini adalah berupa lembar pertanyaan (kuesioner) \& wawancara yang berisi daftar pertanyaan tentang kebiasaan sarapan sebagai determinan prestasi belajar siswa. Data kemudian diolah dan dianalisis dengan uji statistika Chi Square untuk menguji hipotesis penelitian. Berdasarkan hasil penelitian, ada hubungan antara kebiasaan sarapan dengan perstasi belajar. Diharapkan adanya peningkatan informasi tentang pola hidup sehat baik kepada instansi pendidikan maupun orangtua siswa.
\end{abstract}

Kata kunci : Kebiasaan Sarapan; MTs Nurul Falah; Prestasi Belajar; Siswa SMPN,. 


\section{PENDAHULUAN}

Anak usia sekolah adalah investasi bangsa, karena mereka adalah generasi penerus bangsa. Kualitas bangsa ini ditentukan oleh kualitas anakanak saat ini. Upaya peningkatan kualitas sumber daya manusia harus dilakukan sejak dini, secara sistematis dan berkesinambungan. Tumbuh kembang anak usia sekolah yang optimal tergantung pemberian nutrisi dengan kualitas dan kuantitas yang baik serta benar. Dalam masa tumbuh kembang tersebut pemberian nutrisi atau asupan makanan pada anak tidak selalu dapat dilaksanakan dengan sempurna. Sering timbul masalah terutama dalam pemberian makanan yang tidak benar dan menyimpang. Penyimpangan ini mengakibatkan gangguan pada banyak organ-organ dan sistem tubuh anak (1).

Pendidikan adalah suatu usaha atau kegiatan yang dilakukan dengan sengaja, teratur dan berencana dengan maksud mengubah atau mengembangkan perilaku yang diinginkan. Belajar akan menghasilkan perubahan-perubahan dalam diri seseorang. Untuk mengetahui sampai berapa jauh yang terjadi, perlu adanya evaluasi. Evaluasi terhadap hasil belajar siswa untuk mengetahui sejauh mana telah mencapai sasaran belajar inilah yang disebut sebagai prestasi belajar (2). Berbagai masalah banyak dijumpai dikalangan anak sekolah diantaranya kurangnya pertumbuhan fisik secara optimal. Salah satu faktor yang menentukan adalah masalah gizi. Asupan gizi anak-anak sekolah dibeberapa wilayah di Indonesia sangat memprihatinkan, asupan gizi yang baik setiap harinya dibutuhkan supaya anak-anak ini memiliki pertumbuhan, kesehatan, dan kemampuan intelektual yang baik sehingga menjadi generasi penerus bangsa yang unggul (3).

Para siswa perlu energi di pagi hari untuk memulai setiap kegiatan pagi mereka, sarapan merupakan langkah dalam menghadapi kegiatan tersebut. Beberapa manfaat sarapan yaitu menjaga kesehatan khususnya daya tahan tubuh dan berat badan sehingga para siswa lebih konsentrasi dalam belajar, menjadikan siswa belajar bertanggung jawab dan disiplin, mempengaruhi prestasi belajar dalam arti memiliki daya pikir dan kemampuan mengingat yang lebih tinggi daripada yang tidak sarapan. (4).

Pada anak dengan rentang usia 12 - 18 tahun, sarapan termasuk dalam faktor risiko utama masalah kesehatan dengan proporsi kebiasaan sarapan sebanyak $44,6 \%$ yang terbagi dari kategori tidak pernah sarapan $(5,2 \%)$, jarang sarapan $(4,58 \%)$ \& kadang-kadang sarapan (34,82\%). Faktor-faktor yang kemungkinan terkait dengan perilaku kebiasaan sarapan tersebut seperti peran keluarga dan orangtua serta tersedianya makanan sehat saat di pagi hari. (5). Dari observasi awal di MTs Nurul Falah Juai pada awal Desember 2018, nilai raport siswa semester sebelumnya dengan prestasi belajar rata-rata ke bawah kebanyakannya orangtua \& lingkungan keluarga saat pagi tidak menyiapkan sarapan sehingga berpeluang menimbulkan penurunan prestasi belajar. Tujuan penelitian ini, untuk mengetahui kebiasaan sarapan sebagai determinan prestasi belajar siswa SMP sederajat di kecamatan Juai kabupaten Balangan.

\section{BAHAN DAN METODE}

Penelitian ini merupakan penelitian Survei Analitik dengan menggunakan pendekatan Cross Sectional, dengan cara pendekatan dan observasi atau pengumpulan data sekaligus pada suatu saat (point time opproach). Artinya, tiap subjek peneliti hanya diobservasi sekali saja dengan pengukuran dilakukan terhadap status karakter atau variabel subjek pada saat pemeriksaan (6). Sampel pada penelitian ini adalah total sampling. Data yang sudah dikumpulkan, dilanjutkan dengan pemeriksaan data, pengkodean dan rekapitulasi serta analisis statistik. Analisis pertama yang dilakukan adalah analisis univariat yang penggunaannya pada tiap variabel yang diteliti dan bertujuan memberikan deskripsi melalui tabel distribusi frekuensi. Untuk variabel sarapan terdiri dari 2 kategori yaitu biasa sarapan pagi (bila frekuensi sarapan pagi dalam 1 minggu sebanyak 4 kali atau lebih) dan tidak biasa sarpan pagi (bila frekuensi sarapan pagi dalam 1 minggu kurang dari 4 kali) (7). Pada variabel prestasi belajar dilihat dari rata-rata jumlah nilai rapot per smester dengan kategori sangat baik (86-100), baik (71-85) dan cukup (56-70). Kemudian dilanjutkan dengan uji Chi-Square agar dapat mengetahui pengaruh kebiasaan sarapan dengan prestasi belajar pada siswa.

\section{HASIL DAN PEMBAHASAN}

Hasil Penelitian

Analisis Univariat 
Tabel 1. Distribusi Frekuensi variabel kebiasaan sarapan dan prestasi belajar di MTs Nurul Falah Juai Kecamatan Juai Kabupaten Balangan, tahun 2019

\begin{tabular}{lcc}
\hline \multicolumn{1}{c}{ Variabel } & n & \% \\
\hline $\begin{array}{l}\text { Kebiasaan Sarapan } \\
\text { Biasa sarapan pagi }\end{array}$ & 59 & 46,5 \\
Tidak Biasa sarapan & 68 & 53,5 \\
pagi & & \\
Prestasi Belajar & 58 & 45,7 \\
Sangat Baik & 56 & 44,1 \\
Baik & 13 & 10,2 \\
Cukup & & 100 \\
\hline Jumlah & 127 & \\
\hline
\end{tabular}

Berdasarkan tabel 1 diatas menunjukkan bahwa sebagian besar responden tidak bisa sarapan pagi adalah sebesar 68 (53,5\%), Sebagian besar responden yang memiliki prestasi belajar dengan kategori sangat baik yaitu 58 (45,7\%).

\section{Analisis Bivariat}

Tabel 2 Hubungan kebiasaan Sarapan dengan Prestasi Belajar di MTs Nurul Falah Juai Kecamatan Juai Kabupaten Balangan, tahun 2019

\begin{tabular}{|c|c|c|c|c|c|c|c|c|c|}
\hline \multirow[t]{3}{*}{ Variabel } & \multicolumn{6}{|c|}{ Prestasi Belajar } & \multirow{2}{*}{\multicolumn{2}{|c|}{ Jumlah }} & \multirow[t]{3}{*}{ P value } \\
\hline & \multicolumn{2}{|c|}{ Sangat Baik } & \multicolumn{2}{|c|}{ Baik } & \multicolumn{2}{|c|}{ Cukup } & & & \\
\hline & $\mathrm{n}$ & $\%$ & $\mathrm{n}$ & $\%$ & $\mathrm{n}$ & $\%$ & $\mathrm{n}$ & $\%$ & \\
\hline Kebiasaan Sarapan & & & & & & & & & \\
\hline Biasa sarapan pagi & 32 & 54,2 & 25 & 42,4 & 2 & 3,4 & 59 & 100 & 0,032 \\
\hline $\begin{array}{l}\text { Tidak Biasa sarapan } \\
\text { pagi }\end{array}$ & 26 & 38,2 & 31 & 45,6 & 11 & 16,2 & 68 & 100 & \\
\hline
\end{tabular}

\section{PEMBAHASAN}

Berdasarkan penelitian yang dilakukan di MTs Nurul Falah Juai di dapatkan data bahwa kebiasaan sarapan merupakan salah satu faktor yang mempengaruhi kualitas prestasi belajar murid.

Dari Tabel 2 didapat data bahwa kebiasaan sarapan dengan kategori "biasa" yaitu sebanyak 59 responden dengan persentase $(100 \%)$ dengan jumlah responden yang memiliki prestasi belajar dengan kategori "sangat baik" berjumlah 32 (54,2\%) sedangkan responden yang memiliki prestasi belajar dengan kategori "baik" berjumlah 25 (42,4\%) dan responden yang memiliki prestasi belajar dengan kategori "cukup" berjumlah 2 (3,4\%). untuk responden yang memiliki kebiasaan sarapan dengan kategori "tidak biasa" sebanyak 68 responden dengan persentase (100\%) dengan jumlah responden yang memiliki prestasi belajar dengan kategori "sangat baik" berjumlah 26 (38,2\%) sedangkan responden yang memiliki prestasi belajar dengan kategori "baik" berjumlah 31 (45,6\%) dan responden yang memiliki prestasi belajar dengan kategori "cukup" berjumlah 11 (16,2\%).

Dari hasil uji statistik Chi Square di dapatkan nilai $\mathrm{P}$ yaitu 0,032 , yang berarti nilai $\mathrm{P}=0,032<\mathrm{a}$ 0,05, dengan demikian maka Ho = ditolak, artinya ada hubungan yang signifikan antara variabel bebas dengan variabel terikat di MTs Nurul Falah Juai.

Hasil ini sesuai dengan penelitian yang dilakukan oleh Siska Ristiana (8) di kabupaten Deli Serdang Sumatra Utara, yang menyatakan bahwa ada hubungan antara kebiasaan sarapan dengan prestasi belajar siswa, juga Elda Khalida dkk (9) yang melihat dari prestasi belajar mata pelajaran matematika \& Bahasa Indonesia menyatakan terdapat hubungan yang bermakna dengan kebiasaan sarapan. Pernyataan tersebut juga diperkuat oleh Mohammad Mochtar dkk (10), yang 
mengatakan bahwa antara sarapan dengan kemampuan konsentrasi pada remaja lebih tinggi secara bermakna dibandingkan kelompok remaja yang tidak sarapan. Bagi anak sekolah, sarapan dapat meningkatkan konsentrasi belajar dan memudahkan menyerap pelajaran sehingga meningkatkan prestasi belajar. Menurut Judarwanto (1) investasi bangsa pada anak usia sekolah, karena mereka adalah generasi penerus bangsa. Kualitas bangsa di masa depan ditentukan oleh kualitas anak-anak saat ini. Upaya peningkatan kualitas sumber daya manusia sejak dini harus dilakukan, berkesinambungan dan sistematis.

\section{KESIMPULAN DAN SARAN}

Ada hubungan antara variabel bebas yaitu kebiasaan sarapan dengan variabel terikat yakni prestasi belajar (nilai $\mathrm{P}=0,032<a 0,05$ ). Hal ini menunjukan bahwa kebiasaan sarapan merupakan faktor yang mempengaruhi kualitas prestasi belajar pada siswa MTs Nurul Falah Juai. Kepada instansi pendidikan terkait untuk lebih meningkatkan informasi tentang pola hidup sehat di antaranya penerapan kebiasaan sarapan pada siswa dengan cara pihak sekolah menyediakan kantin sehat sekolah sebelum masuk pembelajaran secara gratis agar para siswa terjamin sarapannya dan tidak mudah jajan sembarangan yang belum tentu terjamin kebersihan dan kualitas makanannya. Bagi orang tua siswa untuk lebih bisa menjaga dan mengawasi perkembangan prestasi belajarnya, agar setiap permasalahan yang muncul pada diri anak bisa terdeteksi secara dini, sehingga dapat langsung ditangani secara baik. Bagi siswa untuk lebih bisa mengetahui, memahami serta menerapkan pola hidup sehat, sehingga upaya untuk meningkatkan prestasi belajar bisa terwujudkan.

\section{DAFTAR PUSTAKA}

1. Judarwanto W. Perilaku makan Anak sekolah. http:/ /gizi.depkes.go.id/wpcontent/uploads/2012/05/perilaku-makananak-sekolah. 2012.

2. Prof. Dr. H. Djaali. Psikologi Pendidikan. Edisi Pertama, cetakan ke-8. Jakarta : PT Bumi Aksara; 2014.

3. Santoso S. Kesehatan dan Gizi, Cetakan ke-3. Jakarta : Rineka Cipta; 2013.
4. Handayani, Ery. Manfaat Sarapan untuk Efektivitas Belajar Siswa. Semarang : SMP Islam Terpadu PAPB; 2018. https://smpislampapb.sch.id/official/2018/02/ 17/manfaat-sarapan-untuk-efektivitas-belajarsiswa/

5. Kusumawardani, Nunik, dkk. Hasil Survey Nasional Kesehatan Berbasis Sekolah di Indonesia. Perilaku Berisiko Kesehatan Pada Pelajar SMP dan SMA di Indonesia. Jakarta : Puslitbang Upaya Kesehatan Masyarakat Badan Litbangkes Kementerian Kesehatan RI. 2015

6. Notoadmodjo S. Metodologi Penelitian Kesehatan. Edisi Revisi . Jakarta: PT Rineka Cipta; 2010.

7. Niswah Ilyatun, dkk. 2014. Kebiasaan Sarapan, Status gizi, dan Kualitas hidup Remaja SMP Bosowa Bina Insani Bogor. Jurnal Gizi dan Pangan. 2014;9(2):97-102.

8. Ristiana, Siska M., 2009. Hubungan Pengetahuan, Sikap, tindakan Sarapan Dengan Status Gizi Dan Indeks Prestasi Anak Sekolah Dasar Di SD Negeri NO.101835 Bingkawan Kecamatan Sibolangit Tahun 2009 [Skripsi]. Medan : Universitas Sumatera Utara; 2009.

9. Khalida Elda, Fadlyana Eddy, Somasetia Dadang Hudaya. Hubungan Kebiasaan Sarapan Dengan Prestasi Belajar dan Fungsi Kognitif Pada Anak Sekolah Dasar. Sari Pediatri. 2015;17(2):89-94.

10. Muchtar M, Julia M, Gamayanti IL. Sarapan dan Jajan Berhubungan dengan Kemampuan Konsentrasi Remaja. Jurnal Gizi Klinik Indonesia. 2011;8(1)28-. 